\title{
Theoretical and Empirical Basis of Optimal Tax Burden in Georgia
}

\author{
Tamar Kbiladze
}

\begin{abstract}
High speed of globalization has created inevitability of ensuring objectives of sustainable development of economics and optimally determined taxes can play very important role in it, which is the main factor for formation of tax burden. This in itself is an important leverage for achieving the sustainable development and prosperity of society. Generally, state regulates economy of the country through the taxes because it is the main tool for shaping the country's revenue part of the budget. The aim of the paper is to determine the optimal tax burden for the economy of Georgia. In order to achieve above mentioned goal numerous research methods have been applied: Qualitative, quantitative, correlation/regression analysis. As a result, it has been received that optimal tax burden which is controllable, anticipatory and oriental parameter for the economy of Georgia ranges from $13.6 \%$ to $17.6 \%$.
\end{abstract}

Index Terms-Empirical research, laffer curve, optimal tax burden, sustainable development.

\section{INTRODUCTION}

In recent years, in Georgia, as a result of the tax reform the number of taxes were reduced from 21 to 6 , as well as tax rates were reduced [1]. Despite of these facts, tax burden needs further optimization. As it is known, tax burden is calculated as for the country as a whole, it is calculated as well as for institutional units (corporation, enterprise) and for population. Sustainable development of economy and business promotion greatly depends on heaviness and lightness of tax burden. Thus, it is very important and difficult scientific and practical problem to determine the optimal size of tax burden. There still does not exists universally accepted methodology for determining optimal tax rates, which is the main issue for optimal tax burden formation.

\section{ANALYSIS AND FINDINGS}

In order to study the problem, I have determined the methodology which is dedicated for determination of optimal tax rates. As we know taxes have dual nature. The first part is paid by an enterprise for the value of production (services), which can be called as a compulsory tax. As for the second part of the tax it should be paid by corporation for the realization of common state goals such as ensuring country's defense, public education and health care, contribution of economic development. How should we calculate first and

Manuscript received May15, 2015; revised December 2, 2015

Tamar Kbiladze is with Ivane Javakhishvili Tbilisi State University, 2, University str., 0186, Tbilisi, Georgia (e-mail: tako_kbiladze@yahoo.com, tamar.kbiladze@tsu.ge). second part of taxes? A research was conducted by me to determine corporate tax rate. On the basis of National Statistics Office of Georgia I have investigated 9735 enterprises. Research has shown that on the share of the first part of corporate tax is $12 \%$ of enterprise profit. According to country's tax code, corporate tax is $15 \%$. In my opinion, the difference between official rate of $15 \%$ and $12 \%$ is the second part of the tax. How can we define the second part? In this way we have to study opinions of experts, politicians, governmental agencies, non-governmental organizations, a survey should be conducted to determine which problem should be considered as a main and first problem between the next ones: country's defense capacity, public order, health care, economic development. Also it's very important to take in consideration the situation which exists in the EU member states, I mean that our rates should be closer to EU average rates. In the same way should be calculated rates of other taxes, so the first part of taxes is the cost which is paid by corporations for receiving income, taxes for consumption and accumulation. The second part should be determined by questioning experts and making surveys. Tax rates should be calculated not for short-term but for long run perspectives and after 5 or 10 years it should be reviewed by taking in consideration the results of new surveys. After determining optimal tax rates it should be calculated optimal tax burden for corporation, as well as for country. Table I shows tax burden in Georgia from 2003 to 2012.

\begin{tabular}{|c|c|c|c|c|c|c|c|c|c|c|}
\hline Indicator & $\stackrel{N}{\mathscr{8}}$ & F & $\begin{array}{l}N \\
\mathscr{O} \\
\mathcal{O}\end{array}$ & 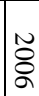 & 奋 & $\underset{\infty}{\mathbb{D}}$ & $\begin{array}{l}n \\
8 \\
\delta\end{array}$ & 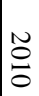 & $\stackrel{N}{\stackrel{O}{O}}$ & $\begin{array}{l}N \\
\stackrel{0}{0} \\
\end{array}$ \\
\hline $\begin{array}{l}\text { GDP at current } \\
\text { prices, mln.Gel }\end{array}$ & $\begin{array}{l}\infty \\
\mathscr{\perp} \\
\stackrel{\perp}{\perp}\end{array}$ & $\begin{array}{l}\infty \\
\infty \\
\infty\end{array}$ & 昰 & w్ & $\begin{array}{l}\vec{\sigma} \\
0 \\
0 \\
+\end{array}$ & $\begin{array}{l}\text { ¿o } \\
\text { uे } \\
\text { ur }\end{array}$ & స̃ & $\begin{array}{l}\text { D } \\
\text { J } \\
\mathbb{E} \\
\omega\end{array}$ & $\stackrel{N}{N}$ & $\underset{\infty}{\tilde{\omega}}$ \\
\hline $\begin{array}{l}\text { Tax Revenues } \\
\text { at current } \\
\text { prices, mln.Gel }\end{array}$ & 尺̊ & 卢 & $\begin{array}{l}\vec{b} \\
\infty \\
\omega\end{array}$ & 古 & హ్ & $\underset{\omega}{\vec{\omega}}$ & $\underset{\infty}{w}$ & $\begin{array}{l}+ \\
\infty \\
9\end{array}$ & 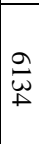 & gे \\
\hline Tax Burden $\%$ & & $\vec{r}$ & 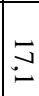 & $\begin{array}{l}\overline{6} \\
\text { in }\end{array}$ & $\stackrel{N}{a}$ & $\underset{+}{+}$ & $\stackrel{N}{N}$ & $\underset{\sim}{\omega}$ & $\begin{array}{l}\sim \\
\sim \\
\sim\end{array}$ & $\begin{array}{l}n \\
u \\
u\end{array}$ \\
\hline
\end{tabular}

Source: Calculated by the author on the base of National Statistics Office of Georgia [2]

As Table I shows tax burden in Georgia is gradually worsening since 2003 and in 2012 compared with 2003 has increased two times and more. Although, it should be mentioned that tax burden in Georgia is lowest in comparison with European Union countries [3]. As international practice shows, generally tax revenue increases in the post-election 
years [4].

According to economic activities tax burden is lowest in trade and the highest is in mining industry enterprises. Generally, such trend has been established during burden analysis: Tax burden is high in good manufacturing fields and is low in service sectors.

Despite the fact that the tax burden is different by large, medium and small enterprises, as well as by economic activities of enterprises, more detailed information about lightness and heaviness of tax burden can be seen by distribution of tax burden on enterprises by decile groups.

It is investigated and analyzed each company's tax burden by the year 2011 and based on analysis of decile groups of burden I have investigated that in terms of average level of tax burden in enterprises $(28,11 \%), 10 \%$ of enterprises who have the most light burden have $8,7 \%$ of whole burden of enterprises, also $10 \%$ of enterprises who have the biggest burden have $53,5 \%$ of whole burden, so tax burden of largest enterprises is 6 times more than burden of smallest enterprises whereas according to tax code enterprises irrespective of their size and type of activities are paying the same interest rate taxes. The only exceptions are individual entrepreneurs who benefit from preferential tax rates. Thus, analysis of tax burden and according to my research it is obvious that nowadays the existing tax burden in Georgia needs further optimization which is the most important factor for sustainable development of country's economy.

In order to have a clearer representation about the optimal level of tax burden on macro level we have to build Laffer curve for economy of Georgia according to the years 1996 2012. Laffer dynamic curve by interpretation of Balatsky is given by the following formula [5]:

$$
x=a \cdot q+b \cdot q^{2}
$$

where $a$ and $b$ are estimated parameters.

(1) Model allows us to obtain three indicators at the same time. They are the dynamic Laffer point $q^{*}$, the static Laffer point $q^{* *}$, and the maximum economic growth rate $x^{*}$. Model (1) shows the correlation between pace of GDP growth and tax rate.

$$
x=\frac{x_{t}-x_{t-1}}{x_{t-1}} \text { is the pace of GDP growth; }
$$

$q=\frac{T}{x}-$ is the tax burden, which is calculated as the sum of the tax revenue to GDP for the year.

In order to evaluate optimal tax burden, we have to analyze official statistical data (Table II).

TABLE II: ANALYZE OFFICIAL STATISTICAL DATA

\begin{tabular}{|c|c|c|}
\hline Year & $\begin{array}{c}\text { GDP - 1996 year } \\
\text { prices }\end{array}$ & $\begin{array}{c}\text { Tax revenues - } \\
1996 \text { year prices }\end{array}$ \\
\hline 1996 & 3868,475 & 386,2 \\
\hline 1997 & 4275,402 & 727,877 \\
\hline 1998 & 4408,149 & 663,025 \\
\hline 1999 & 4534,630 & 736,916 \\
\hline 2000 & 4617,992 & 753,051 \\
\hline 2001 & 4839,907 & 833,985 \\
\hline
\end{tabular}

\begin{tabular}{|l|l|l|}
\hline 2002 & 5104,836 & 887,175 \\
\hline 2003 & 5669,334 & 890,768 \\
\hline 2004 & 6001,536 & 964,341 \\
\hline 2005 & 6577,269 & 975,769 \\
\hline 2006 & 7194,477 & 1043,549 \\
\hline 2007 & 8082,121 & 1223,581 \\
\hline 2008 & 8269,145 & 1230,448 \\
\hline 2009 & 7956,921 & 1209,150 \\
\hline 2010 & 8454,469 & 1224,518 \\
\hline 2011 & 9060,955 & 1349,158 \\
\hline 2012 & 9615,026 & 1450,578 \\
\hline
\end{tabular}

Source: Calculated by the author on the base of National Statistics Office of Georgia

Regression analysis in Excel is as follows:

SUMMARY OUTPUT

\section{Regression Statistics}

Multiple F 0,998816

R Square 0,997634

Adjusted I 0,930809

Standard I 0,055063

Observati $\quad 17$

\begin{tabular}{|c|c|c|c|c|c|}
\hline & $d f$ & SS & $M S$ & $F$ & gnificance \\
\hline Regressio & 2 & 19,17362 & 9,586811 & 3161,945 & $2,57 \mathrm{E}-19$ \\
\hline Residual & 15 & 0,045479 & 0,003032 & & \\
\hline Total & 17 & 19,2191 & & & \\
\hline
\end{tabular}

ANOVA

\begin{tabular}{|c|c|c|c|c|c|c|c|c|}
\hline \multicolumn{3}{|c|}{ Coefficientsandard Err } & \multirow{2}{*}{$\begin{array}{l}t \text { Stat } \\
\# \mathrm{~N} / \mathrm{A}\end{array}$} & \multirow{2}{*}{$\begin{array}{c}P \text {-value } \\
\text { \#N/A }\end{array}$} & \multicolumn{4}{|c|}{ Lower 95\% Upper 95\%ower 95,0\%pper 9} \\
\hline & 0 & & & & & & & \\
\hline & & & & & & & & \\
\hline ariable & 8,671 & 643468 & $-8,831$ & $=-07$ & 2,8312 & 44,5108 & 72,8312 & $-44,5$ \\
\hline
\end{tabular}

\begin{tabular}{l|l|l|l|}
\hline Total & 17 & 19,2191 \\
\hline
\end{tabular}

As we can see the model satisfies the statistical estimation of the parameters set for him. Laffer curve for the economy of Georgia can be figured out as the following:

$$
x=16,014 q-58,671 q^{2}
$$

By solving Parabola, we will see that the optimal tax burden, i.e. the dynamic Laffer point, $q=13,6 \%$ and the optimal economic growth is $9,3 \%$, the static Laffer point is equal to $17,6 \%$. If we look at the economy's real growth data, as well as tax burden data (Table III), we can evaluate size of deviation from optimal level of this parameter for each year.

TABLE III: REAL GROWTH OF GDP (\%, IN COMPARISON WITH THE PREVIOUS YEAR) AND TAX BURDEN IN GEORGIA, 1996-2012

\begin{tabular}{|c|c|c|}
\hline Year & Real growth rate of economy & Tax Burden \\
\hline 1996 & 1,113 & 0,099 \\
\hline 1997 & 1,1053 & 0,170 \\
\hline 1998 & 1,0313 & 0,150 \\
\hline 1999 & 1,029 & 0,163 \\
\hline 2000 & 1,018 & 0,163 \\
\hline 2001 & 1,048 & 0,172 \\
\hline 2002 & 1,055 & 0,174 \\
\hline 2003 & 1,111 & 0,157 \\
\hline 2004 & 1,059 & 0,160 \\
\hline 2005 & 1,096 & 0,148 \\
\hline 2006 & 1,094 & 0,145 \\
\hline 2007 & 1,123 & 0,151 \\
\hline 2008 & 1,023 & 0,149 \\
\hline 2009 & 0,962 & 0,152 \\
\hline 2010 & 1,062 & 0,145 \\
\hline 2011 & 1,072 & 0,149 \\
\hline 2012 & 1,061 & 0,151 \\
\hline
\end{tabular}

Source: Calculated by the author on the base of National Statistics Office of Georgia 


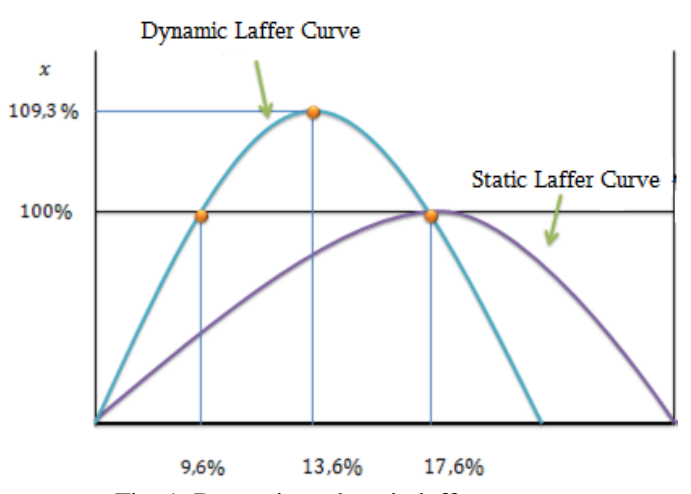

Fig. 1. Dynamic and static laffer curves.

Static Laffer curve points indicate state of economy where GDP maintains constant pace of growth, which is equal to one. Fiscal policy action range is within these points. Deviation beyond this interval will entail economic crisis of the country. Estimated value of static Laffer points for economy of Georgia is respectively $9.6 \%$ and $17.6 \%$. This means that tax burden lower than $9.6 \%$ will cause country's economic downturn, as well as an increase of the tax burden above $17,6 \%$ will bring the economy of the country in recessive condition (Fig. 1).

In terms of optimality, it is rational if meaning of tax burden will be closer to $13.6 \%$ - from the left, however, for providing the necessary budgetary expenditures, executive and legislative bodies who are compiling fiscal policy, probably, will choose parameters of tax burden from $13.6 \%-17.6 \%$. Under these conditions, in addition to higher budget revenues, the economy is growing accordingly. Thus, interval of tax burden between $13.6 \%-17.6 \%$ is controllable, anticipatory and oriental parameter.

The empirical analysis comprises a state level and micro level approach [6]. It should be mentioned that tax burden on micro level (tax burden of enterprises) plays significant role in development of country's economy.

Tax burden on level of enterprises is calculated by different ways. These are: taxes paid by enterprises in proportions to intermediate consumption, share of taxes paid by enterprises in total income or taxes paid by enterprises in proportion to value added.

In order to calculate tax burden of enterprises in 2013, a special research was conducted. As we know burden of enterprise $=($ corporate $\operatorname{tax}+$ property tax + import duty + income tax + excise tax) / total income.

In 2013, 59028 enterprises are registered in informational database of National Statistics Office of Georgia. We investigated 8515 enterprise by using combined system of observation. Large enterprises - 3323, Medium enterprises 1949, small enterprises-3243.

Selection was implemented by selecting stratified groups and selection of enterprises within the groups was managed by simple random sampling. Information was processed by computer programs: MS Access; MS excel, SPSS.

From selected 8515 enterprises, calculation of each enterprise's tax burden was done by extracting data about individual entrepreneurs, on the grounds that this type of institutional units according to Tax Code have certain benefits. According to our research, we received next figure of tax burden (Table IV).
TABLE IV: TAX BURDEN BY TYPES (SIZE) OF ENTERPRISES

\begin{tabular}{|c|c|c|}
\hline $\begin{array}{l}\text { Types of } \\
\text { enterprises }\end{array}$ & Number of enterprises & $\begin{array}{l}\text { Average tax burden } \\
(\%)\end{array}$ \\
\hline Large & 3323 & 24,7 \\
\hline Medium & 1949 & 26,1 \\
\hline Small & 3243 & 28,3 \\
\hline Total & 8515 & 26,4 \\
\hline
\end{tabular}

Source: Calculated by the author on the base of National Statistics Office of Georgia

As we see from above mentioned data, tax burden of large enterprises is lower by 2 percentage points than the total average tax burden of whole enterprises. This difference is even more noticeable between large, medium and small enterprises. In particular, tax burden of small enterprises is more by 3,6\% than tax burden of large enterprises.

Analysis of tax burden by types of economic activities of enterprises has significant importance. It has following form(Table V):

TABLE V: TAX BURDEN OF ENTERPRISES BY TYPE OF ECONOMIC ACTIVITIES

\begin{tabular}{|c|c|c|}
\hline Section & Economic activities of enterprises & $\begin{array}{c}\text { Average tax } \\
\text { burden } \%\end{array}$ \\
\hline A & Agriculture, hunting and forestry & 31,4 \\
\hline B & Fishing & 30,5 \\
\hline C & Mining & 28,0 \\
\hline D & Conufacturing & 25,7 \\
\hline E & Electricity, gas and water supply & 25,5 \\
\hline F & $\begin{array}{c}\text { Trade, repair of motor vehicles and } \\
\text { household appliances }\end{array}$ & 23,1 \\
\hline G & Hotels and Restaurants & 25,1 \\
\hline H & Transport and communications & 27,4 \\
\hline K & Operations with real estate and & 30,1 \\
\hline L & Education & 31,1 \\
\hline M & Health care and social services & 32,4 \\
\hline N & $\begin{array}{l}\text { Social and personal service } \\
\text { activities }\end{array}$ & 33,7 \\
\hline O & atal & 26,4 \\
\hline Total
\end{tabular}

Source: Calculated by the author on the base of National Statistics Office of Georgia

During analysis of tax burden such a trend has been established: In 2013, the tax burden is high in commodity producer fields and tax burden is low in service sectors.

Although the tax burden of enterprises are different in large, medium and small enterprises, as well as by types of economic activities of enterprises, we can have more detailed analysis about lightness and heaviness of tax burden by distribution of enterprises by decile groups (di). In this case, the tax burden of enterprises should be divided into 10 equal parts by the ranked columns. The first decile (d1) divides the aggregate accordingly to $\frac{1}{10}-\frac{9}{10}$. The second decile (d2) divides aggregate accordingly to $\frac{2}{10}-\frac{8}{10}$ and etc.

We calculated decile in the same way as median is calculated.

Particularly,

$$
d_{1}=x d_{1}+i \cdot \frac{\left(\frac{1}{10} \sum F-S d_{1}-1\right)}{f d_{1}}
$$




$$
d_{9}=x d_{9}+i \cdot \frac{\left(\frac{9}{10} \sum F-S d_{9}-1\right)}{f d_{9}}
$$

Afterwards, enterprises being in our observation area were divided into 10 parts (Table VI):

TABLE VI: DISTRIBUTION OF ENTERPRISES BY DECILE GROUPS ACCORDING TO BURDEN SIZE

\begin{tabular}{|c|c|c|c|}
\hline $\begin{array}{c}\text { Number of } \\
\text { group }\end{array}$ & $\begin{array}{c}\text { Minimum of } \\
\text { Burden }\end{array}$ & $\begin{array}{c}\text { Maximum of } \\
\text { Burden }\end{array}$ & $\begin{array}{c}\text { Number of } \\
\text { enterprises }\end{array}$ \\
\hline 1 & 20,002 & 26,996 & 2383 \\
\hline 2 & 26,996 & 33,988 & 805 \\
\hline 3 & 33,988 & 40,980 & 189 \\
\hline 4 & 40,980 & 47,973 & 58 \\
\hline 5 & 47,973 & 54,966 & 30 \\
\hline 6 & 54,966 & 61,959 & 12 \\
\hline 7 & 61,959 & 68,952 & 12 \\
\hline 8 & 68,952 & 75,945 & 11 \\
\hline 9 & 75,945 & 82,937 & 5 \\
\hline 10 & 82,937 & 89,930 & 9 \\
\hline
\end{tabular}

Source: Calculated by the author on the base of National Statistics Office of Georgia

Number of first decile group:

$$
\begin{gathered}
N d_{1}=\left(\sum f\right) \cdot \frac{1}{10}=\frac{3514}{10}=351,4 \\
d_{1}=20,002+6,992 \cdot \frac{351,4-0}{2383}=21,033
\end{gathered}
$$

Ninth decile group number:

$$
\begin{gathered}
N d_{9}=\left(\sum f\right) \cdot \frac{9}{10}=316,26 \\
d_{9}=26996+6992 \cdot \frac{3162,6-2383}{805}=33,7
\end{gathered}
$$

By given calculations, we can conclude that according to tax burden, $10 \%$ of low burden enterprises have $21.03 \%$ of whole burden, while also $10 \%$ of high burden enterprises have $33,7 \%$ of whole burden, which is 1.6 times higher than the lowest.

\section{CONCLUSION}

Analysis of tax burden and according to our research, it is obvious that nowadays existing tax burden in Georgia needs further optimization which is the most important factor for sustainable development of country's economy.

In order to achieve sustainable development of economy and prosperity of society, oriental parameter of tax burden on macro level should range from $13.6 \%$ to $17.6 \%$ and tax rates should differ by size of enterprises (large, medium, small) as well as by activities of enterprises (trade, extractive industry, energy, manufacturing, etc.), whereas according to tax code of Georgia enterprises irrespective of their size and type of activities are paying the same interest rate taxes. All above mentioned factors are the basis of optimal tax burden in Georgia.

\section{REFERENCES}

[1] Tax Code of Georgia, Legislative Registrar, $N$ 3591, Tbilisi, Georgia, 2010.

[2] National Statistics Office of Georgia. (2015). [Online]. Available: http://geostat.ge/index.php?action=page\&p_id=119\&lang=eng

[3] Eurostat News Release. (June 2014). [online]. Available: http://ec.europa.eu/taxation_customs/resources/documents/taxation/ge n_info/economic_analysis/tax_structures/2014/pr_92-2014_en.pdf

[4] C. Ebeke and D. Olcer, "Fiscal policy over the election cycle in low income countries," International Monetary Fund Working Paper, 2013.

[5] E. V. Balatsky and N. A. Ekimova, "Fiscal policy and economic growth," Society and Economy, pp. 4-5, 2011.

[6] T. Bonke, B. Jochimsen, and C. Schroder, "Fiscal federalism and tax administration, evidence from Germany," DIW Berlin, 2013.

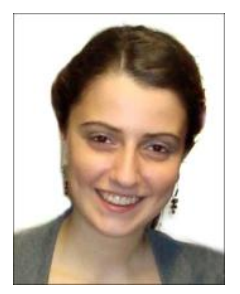

Tamar Kbiladze was born on May 1, 1988, in Tbilisi, Georgia. She has completed her doctoral studies in business administration at Ivane Javakhishvili Tbilisi State University. During her studies, she was an exchange student at Vilnius University, Faculty of Economics and International Business School of Vilnius, Lithuania, Faculty of Business.

She works as an invited associate professor at Ivane Javakhishvili Tbilisi State University, Georgia; as well as a project manager at National Agency of Public Registry, Ministry of Justice, Tbilisi Georgia. At different times, she was invited as an assistant professor at Ivane Javakhishvili Tbilisi State University, Georgiia; as well as an intern at Potsdam University, Germany, Faculty of economics and social sciences. Besides, she has worked as an assistant of the CEO at Partnership Fund, Business Consultant at Public Health Development Assistance Fund.

She has interests in the area of taxation, macroeconomics, corporate finance. 